\title{
Measurement of the electron attachment properties of SF5CF3 and comparison to SF6
}

\section{Journal Article}

Author(s):

Chachereau, Alise (D); Franck, Christian (1)

Publication date:

2017-11-08

Permanent link:

https://doi.org/10.3929/ethz-b-000184530

Rights / license:

In Copyright - Non-Commercial Use Permitted

Originally published in:

Journal of Physics D: Applied Physics 50(44), https://doi.org/10.1088/1361-6463/aa8b9e 


\section{This is a post-refereeing copy of the manuscript resubmitted to IOP before acceptance (Accepted version).}

This is an author-created, un-copyedited version of an article published in Journal of Physics D: Applied Physics. IOP Publishing Ltd is not responsible for any errors or omissions in this version of the manuscript or any version derived from it. The Version of Record is available online at https://doi.org/10.1088/1361-6463/aa8b9e 


\title{
Measurement of the electron attachment properties of $\mathrm{SF}_{5} \mathrm{CF}_{3}$ and comparison to $\mathrm{SF}_{6}$
}

\author{
A. Chachereau, C. M. Franck \\ Power Systems and High Voltage Laboratories, ETH Zurich, CH-8092 Zurich, \\ Switzerland \\ E-mail: alisec@ethz.ch (A. Chachereau) and cfranck@ethz.ch (C. M. Franck)
}

\begin{abstract}
.
The electron attachment properties of $\mathrm{SF}_{5} \mathrm{CF}_{3}$ are experimentally investigated using a pulsed Townsend setup. Different $\mathrm{SF}_{5} \mathrm{CF}_{3} / \mathrm{N}_{2}$ and $\mathrm{SF}_{5} \mathrm{CF}_{3} / \mathrm{CO}_{2}$ mixtures, with $\mathrm{SF}_{5} \mathrm{CF}_{3}$ mole fractions ranging from $2 \times 10^{-4}$ to 1 , are characterized. The effective ionization rate coefficient, electron drift velocity and reduced longitudinal electron diffusion coefficient in these mixture are obtained. For low mole fractions of $\mathrm{SF}_{5} \mathrm{CF}_{3}$, the effective ionization rate coefficient is compared to calculations from available electron scattering cross sections, and is also used for estimating the electron attachment cross section of $\mathrm{SF}_{5} \mathrm{CF}_{3}$. For pure $\mathrm{SF}_{5} \mathrm{CF}_{3}$, the present data is compared to early data from a steady-state Townsend experiment. The presentation of the measurement results is followed by a discussion on the properties of $\mathrm{SF}_{5} \mathrm{CF}_{3}$ and $\mathrm{SF}_{6}$ and their significance for gaseous electrical insulation.
\end{abstract}

PACS numbers: $00.00,20.00,42.10$

Keywords: $\mathrm{CF}_{8} \mathrm{~S}$, trifluoromethylsulphur pentafluoride, electron attachment, electrical insulation.

Submitted to: J. Phys. D: Appl. Phys. 


\section{Introduction}

When trifluoromethylsulphur pentafluoride $\left(\mathrm{SF}_{5}-\mathrm{CF}_{3}\right)$ was synthesized for the first time in 1949 [1], it immediately attracted interest as a potentially good electrical insulator due to its high number of fluorine atoms, its low boiling point $\left(-20^{\circ} \mathrm{C}[2]\right)$ and its similarity to $\mathrm{SF}_{6}$. Sulphur hexafluoride $\left(\mathrm{SF}_{6}\right)$ is indeed widely used in its gaseous form as an electrical insulator for high voltage equipment, such as gas insulated lines, gas insulated substations and switchgear. The electric strength of $\mathrm{SF}_{5} \mathrm{CF}_{3}$ was found to be superior to that of $\mathrm{SF}_{6}$ [3], $\mathrm{SF}_{5} \mathrm{CF}_{3}$ is therefore an excellent insulating gas. However, in the same work $\mathrm{SF}_{5} \mathrm{CF}_{3}$ was found to dissociate rapidly and completely into $\mathrm{SF}_{4}$ and $\mathrm{CF}_{4}$ during electrical breakdown, and the produced $\mathrm{SF}_{4}$ and $\mathrm{CF}_{4}$ did not subsequently recombine into $\mathrm{SF}_{5} \mathrm{CF}_{3}$. Therefore, $\mathrm{SF}_{5} \mathrm{CF}_{3}$ is hardly recommended for use in switching applications, where arcing is frequent. Further applications were envisioned for $\mathrm{SF}_{5} \mathrm{CF}_{3}$, such as refrigerant gas [2] and hydrologic tracer [4]. However, the environmental impact of $\mathrm{SF}_{5} \mathrm{CF}_{3}$ regarding global warming has been lately intensely discussed $[5,6,7,8]$, as it was found that $\mathrm{SF}_{5} \mathrm{CF}_{3}$ is a potent greenhouse gas with a 100-year integrated global warming potential (GWP) of 17400 [9] relative to $\mathrm{CO}_{2}$. This compromises the use of $\mathrm{SF}_{5} \mathrm{CF}_{3}$ in the aforementioned applications. The GWP of $\mathrm{SF}_{6}$ is even higher, namely 23500 [9], and atmospheric measurements show an accumulation of atmospheric $\mathrm{SF}_{6}$ and a global emission increase [10, 11]. Therefore, environmentfriendly gases to substitute $\mathrm{SF}_{6}$ in electrical insulation applications are actively sought.

The performance of a gas as an electrical insulator can be assessed by experimental methods, such as swarm experiments, electron beam experiments and breakdown experiments. Swarm experiments such as pulsed or steady-state Townsend setups can be used to measure electron swarm parameters, i.e. rate and transport coefficients, which serve as input for fluid models to simulate electrical discharges. Electron beam experiments serve to measure electron scattering cross sections, which can be used in turn to calculate rate and transport coefficients. These methods are technically challenging and time consuming. Considering the large number of gases that could be investigated, it would be desirable to gain a better understanding of the link between molecular structure and electron attachment properties in order to select good electrical insulators prior to performing experiments. Recently several attempts have been made to correlate the electric strength and boiling point of gases with numerically calculated predictor variables and some useful correlations were identified $[12,13,14,15]$. However, these methods are hindered by the relatively small size of the training data set, that is, the small number of gases for which the electric strength is known.

While $\mathrm{SF}_{5} \mathrm{CF}_{3}$ can hardly be considered as a lowGWP alternative to $\mathrm{SF}_{6}$ in electrical insulation, the comparative study of $\mathrm{SF}_{5} \mathrm{CF}_{3}$ and $\mathrm{SF}_{6}$ could give an insight into the effect of replacing a single $\mathrm{F}$ atom from the $\mathrm{SF}_{6}$ molecule by a $\mathrm{CF}_{3}$ group [15, 16]. For this purpose, the electron attachment properties of $\mathrm{SF}_{5} \mathrm{CF}_{3}$ are experimentally characterized in this work. The electron swarm parameters in pure $\mathrm{SF}_{5} \mathrm{CF}_{3}$ and in $\mathrm{SF}_{5} \mathrm{CF}_{3} / \mathrm{N}_{2}$ and $\mathrm{SF}_{5} \mathrm{CF}_{3} / \mathrm{CO}_{2}$ mixtures are measured in a pulsed Townsend setup, and the data is made available online [17]. The results are compared to previous investigations of $\mathrm{SF}_{5} \mathrm{CF}_{3}$ and $\mathrm{SF}_{6}$, such as measurements of the electron attachment and ionization cross sections of $\mathrm{SF}_{5} \mathrm{CF}_{3}[18,19]$ and $\mathrm{SF}_{6}[20,21]$ in electron beam experiments and measurements of the attachment and ionization rate coefficients of $\mathrm{SF}_{5} \mathrm{CF}_{3}$ in a steady-state Townsend setup [22].

This work starts with the description of the experimental setup, the experimental conditions and the analytic tools used for the measurement analysis and for the comparison of data from different sources. In the second part of this work, measurement results for diluted mixtures of $\mathrm{SF}_{5} \mathrm{CF}_{3}$ in $\mathrm{N}_{2}$ and $\mathrm{CO}_{2}$ are presented. These results are compared to calculations based on $\mathrm{SF}_{5} \mathrm{CF}_{3}$ cross sections from other works. An estimation of the attachment cross section of $\mathrm{SF}_{5} \mathrm{CF}_{3}$ calculated from the present data is also presented. In the third part of this work, measurement results for mixtures with higher $\mathrm{SF}_{5} \mathrm{CF}_{3}$ content in $\mathrm{N}_{2}$ and $\mathrm{CO}_{2}$ are presented, including measurements in pure $\mathrm{SF}_{5} \mathrm{CF}_{3}$, and the latter are compared to early measurements in pure $\mathrm{SF}_{5} \mathrm{CF}_{3}$ from a steady-state Townsend setup. In the last part of this work, the properties of $\mathrm{SF}_{5} \mathrm{CF}_{3}$ and $\mathrm{SF}_{6}$ are discussed.

\section{Methods}

\subsection{Swarm experiment}

The measurements are performed in a pulsed Townsend setup that was described in a previous work [23]. The gases used in this work have the following purity: the $\mathrm{SF}_{5} \mathrm{CF}_{3}$ has a purity of $99 \%$, the $\mathrm{N}_{2}$ has a purity of 6.0 and the $\mathrm{CO}_{2}$ a purity of 5.0. The gases are filled into a stainless steel vessel previously evacuated to a pressure of $\sim 0.5 \mathrm{~Pa}$. The vessel contains two electrodes separated by a distance $d$. A negative high voltage $U$ is applied to the cathode, whereas the anode is grounded. The electrodes are shaped with a Rogowski profile in order to create a homogeneous electric field $E$. The center of the cathode consists in a 12-nanometer-thick palladium film coated on a quartz 
window. A short laser pulse (1.5 ns FWHM) directed at the back of the palladium film, releases $10^{6}$ to $10^{7}$ electrons, which initiate an electron avalanche. The electron swarm drifts in the uniform electric field towards the anode. Upon collision, an electron may ionize a gas molecule, forming a cation and an additional free electron. An electron may also attach to a gas molecule and form an anion. The ions formed by ionization and attachment events drift in the electric field, but are slower than electrons by 2-3 orders of magnitude. The current $I_{\exp }$ resulting of the displacement of all charged particles drifting through the gap is measured at the anode. The measurements are performed at room temperature, for several gas pressures from 2 to $10 \mathrm{kPa}$, and several gap distances between the electrodes from 11 to $17 \mathrm{~mm}$. The applied voltage is varied from $50 \mathrm{~V}$ to $9.5 \mathrm{kV}$. Sample measurements of current transients are shown in figures 2 and 6 . The electron and ion components of the current are separated using an iterative procedure [24], and the electron component $I_{\mathrm{e}}$ is then analyzed.

\subsection{Electron current analysis}

Assuming that the one-dimensional electron density along the propagation axis is Gaussian, the electron current $I_{\mathrm{e}}$ can be expressed analytically for $t \geq 0$ as $[23,24]$

$$
\begin{aligned}
& I_{\mathrm{e}}(t)=\frac{I_{0}}{2} \exp \left(k_{\mathrm{eff}} N t\right)\left(1-\operatorname{erf}\left(\frac{t-T_{\mathrm{e}}}{\sqrt{2 \tau_{\mathrm{D}}} t}\right)\right), \\
& I_{0}=q_{0} N_{\mathrm{e}}(0) / T_{\mathrm{e}}
\end{aligned}
$$

where $I_{0}$ is the electron current at time $t=0, k_{\text {eff }}$ is the effective ionization rate coefficient, $N$ is the number density of the gas, $T_{\mathrm{e}}$ is the electron drift time, which relates to the electron drift velocity $w_{\mathrm{e}}$ via $T_{\mathrm{e}}=d / w_{\mathrm{e}}, \tau_{\mathrm{D}}$ is the characteristic time for longitudinal electron diffusion, which relates to the longitudinal diffusion coefficient $D_{\mathrm{L}}$ via $2 D_{\mathrm{L}}=w_{\mathrm{e}}^{2} \tau_{\mathrm{D}}, N_{\mathrm{e}}(0)$ is the initial number of electrons and $q_{0}$ is the elementary charge. The determination of the effective ionization rate coefficient $k_{\text {eff }}$, the electron drift velocity $w_{\mathrm{e}}$ and the longitudinal electron diffusion coefficient $N D_{\mathrm{L}}$ using this model was described in detail previously [24].

The quantities $k_{\text {eff }}, w_{\mathrm{e}}$ and $N D_{\mathrm{L}}$ depend on the density-reduced electric field $E / N$, given in Townsend $\left(1 \mathrm{Td}=10^{-21} \mathrm{Vm}^{2}\right)$. The final values of $k_{\text {eff }}, w_{\mathrm{e}}$ and $N D_{\mathrm{L}}$ are given with error bars corresponding to the spread of the values obtained in measurements with different electrode gap distances, and the $E / N$ values are also given error bars coming mainly from to the error $\pm 0.1 \mathrm{~mm}$ in the electrode gap distance, which dominates over the errors from the temperature, pressure and voltage measurements.

The electron drift velocity $w_{\mathrm{e}}$ obtained in the present experiment, as mentioned in $[23,25,26]$, is

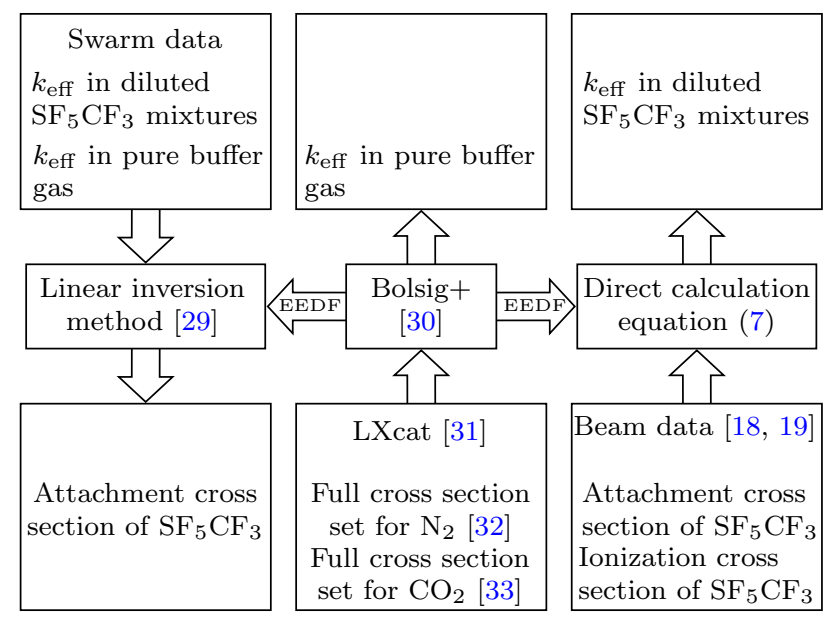

Figure 1. Data flow between rate coefficients (top row) and electron scattering cross sections (bottom row). $k_{\text {eff }}$ : effective ionization rate coefficient. EEDF: electron energy distribution function.

the bulk drift velocity, i.e. the velocity of the center of mass of the electron swarm. In the presence of non-conservative collisions, such as ionization and attachment, it may significantly differ from the flux drift velocity, which is the average velocity of all electrons in the swarm [27, 25, 28].

\subsection{From electron scattering cross sections to rate coefficients and vice versa}

The diagram of figure 1 gives an overview of the methods described in this section, and should as well help the reader to keep track of the data sources.

The effective ionization rate coefficient $k_{\text {eff }}$ is defined as the difference between the ionization and attachment rate coefficients $k_{\mathrm{i}}$ and $k_{\mathrm{a}}$. The relation between $k_{\text {eff }}$ of a gas mixture and the attachment and ionization cross sections of its components is given by (see for instance equation (10) of reference [30])

$k_{\text {eff }}=k_{\mathrm{i}}-k_{\mathrm{a}}$,

$k_{\mathrm{i}}=\sqrt{\frac{2}{m_{\mathrm{e}}}} \int_{0}^{\infty} \sum_{n} x_{n} \sigma_{\mathrm{i}}^{(n)} \varepsilon f \mathrm{~d} \varepsilon$,

$k_{\mathrm{a}}=\sqrt{\frac{2}{m_{\mathrm{e}}}} \int_{0}^{\infty} \sum_{n} x_{n} \sigma_{\mathrm{a}}^{(n)} \varepsilon f \mathrm{~d} \varepsilon$,

where $x_{n}$ is the mole fraction of species $n$ in the mixture, $\sigma_{\mathrm{a}}^{(n)}$ is the total attachment cross section of species $n, \sigma_{\dot{\mathrm{i}}}^{(n)}$ is the total ionization cross section of species $n, m_{\mathrm{e}}$ is the electron mass and $f(E / N, \varepsilon)$ is the electron energy distribution function (EEDF) in the mixture. The EEDF is normalized as follows

$\int_{0}^{\infty} \sqrt{\varepsilon} f \mathrm{~d} \varepsilon=1$

In the particular case where a sample gas is added with a small mole fraction $x \ll 1$ to a buffer gas, the EEDF 
of the gas mixture can be assumed to be the same as that of the pure buffer gas and equations (3-5) simplify to

$k_{\text {eff }}=(1-x) k_{\text {eff }}^{\mathrm{b}}+x \sqrt{\frac{2}{m_{\mathrm{e}}}} \int_{0}^{\infty}\left(\sigma_{\mathrm{i}}-\sigma_{\mathrm{a}}\right) \varepsilon f \mathrm{~d} \varepsilon$,

where $k_{\text {eff }}^{\mathrm{b}}$ is the effective ionization rate coefficient in the pure buffer gas, $\sigma_{\mathrm{i}}$ and $\sigma_{\mathrm{a}}$ are the total ionization and attachment cross sections of the sample gas, and $f$ is the EEDF of the buffer gas.

For the buffer gases $\mathrm{N}_{2}$ and $\mathrm{CO}_{2}$, complete sets of electron scattering cross sections are available, for instance via the LXcat project [31, 34]. In the present work, Biagi's cross section set [32] is used for $\mathrm{N}_{2}$ and the one of Phelps [33] for $\mathrm{CO}_{2}$. The effective ionization rate coefficient $k_{\text {eff }}^{\mathrm{b}}$ and EEDF for these gases are obtained by solving the Boltzmann equation in the twoterm approximation, using the solver Bolsig+ [30].

Using equation (7), only the ionization and attachment cross sections of $\mathrm{SF}_{5} \mathrm{CF}_{3}$ (and not a complete cross section set of $\mathrm{SF}_{5} \mathrm{CF}_{3}$ ) are required for calculating $k_{\text {eff }}$ in diluted $\mathrm{SF}_{5} \mathrm{CF}_{3}$ mixtures. In this work, the ionization cross section of $\mathrm{SF}_{5} \mathrm{CF}_{3}$ from reference [18] and the attachment cross section from reference [19] are used to calculate $k_{\text {eff }}$ for comparison with the present measurement results. The attachment cross section $\sigma_{\mathrm{a}}$ may be estimated through equation (7) using measurements of $k_{\text {eff }}$. Equation (7) can be discretized into a matrix problem of the form $A \sigma_{\mathrm{a}}=b$, where $A$ and $b$ are known (in function of the quantities $k_{\text {eff }}, k_{\text {eff }}^{\mathrm{b}}, f$ and $\sigma_{\mathrm{i}}$ ), and $\sigma_{\mathrm{a}}$ needs to de determined [29]. This constitutes a so-called discrete ill-posed problem. To obtain $\sigma_{\mathrm{a}}$, we use in this work a linear inversion method and a two-term Gaussian expansion method, which have been described previously [29]. The linear inversion method consists in using the singular value decomposition and the Tikhonov regularization with the L-curve method for choosing the regularization parameter. This method has the advantage to yield a unique solution, since it requires no initial guess of the solution, in contrast to iterative methods [28]. For comparison, we also fit a two-term Gaussian expansion, i.e. we approximate the shape of the attachment cross section by two Gaussian functions. This latter method is useful to verify the energy range and magnitude of the attachment cross section.

\subsection{Density-reduced critical electric field}

The density-reduced critical electric field $(E / N)_{\text {crit }}$ of a gas is defined as the $E / N$ ratio for which $k_{\mathrm{eff}}=0$, that is $k_{\mathrm{i}}=k_{\mathrm{a}}$. For $E / N<(E / N)_{\text {crit }}$, electron attachment is dominating over ionization. For $E / N>(E / N)_{\text {crit }}$, ionization dominates over electron attachment. Therefore, $(E / N)_{\text {crit }}$ is a figure of merit for electrical insulation, it is the minimum
$E / N$ ratio for which an electrical discharge can be self-sustained. The $(E / N)_{\text {crit }}$ of a gas mixture cannot be predicted based solely on the $(E / N)_{\text {crit }}$ of the individual components since it depends largely on the electron energy distribution in the gas mixture. A gas mixture is said to have a synergy when its $(E / N)_{\text {crit }}$ is larger that the sum of the $(E / N)_{\text {crit }}$ of its components weighted by their mole fractions in the mixture [35].

\section{Diluted $\mathbf{S F}_{5} \mathbf{C F}_{3}$ mixtures in $\mathbf{N}_{2}$ and $\mathbf{C O}_{2}$}

An overview of the present measurements in diluted $\mathrm{SF}_{5} \mathrm{CF}_{3} / \mathrm{N}_{2}$ and $\mathrm{SF}_{5} \mathrm{CF}_{3} / \mathrm{CO}_{2}$ mixtures is given in table 1.

\subsection{Sample measurements}

Figures 2(a) and (b) show sample measurements of the current versus time in the mixture of $0.51 \% \mathrm{SF}_{5} \mathrm{CF}_{3}$ in $\mathrm{N}_{2}$, along with the result of the iterative procedure [24] to separate the electron and ion components, and the fit of the electron current model (1) to the electron component. In figure 2(a) the current is exponentially decreasing due to dominating electron attachment, whereas in figure 2(b) the current is exponentially increasing due to dominating ionization. The peaks in the signal between $0-20 \mathrm{~ns}$ and $90-110 \mathrm{~ns}$ are overshoots due to underdamping of the measurement circuit.

\subsection{Results of the electron current analysis}

The electron current analysis described in section 1.2 yields the effective ionization rate coefficient $k_{\text {eff }}$, the electron drift velocity $w_{\mathrm{e}}$ and the longitudinal electron diffusion coefficient $N D_{\mathrm{L}}$. These quantities in the considered $\mathrm{SF}_{5} \mathrm{CF}_{3} / \mathrm{N}_{2}$ mixtures are shown in figure 3(a),(b) and (c) respectively, and in figure 4(a),(b) and (c) for the $\mathrm{SF}_{5} \mathrm{CF}_{3} / \mathrm{CO}_{2}$ mixtures, and can also be downloaded from LXcat [17].

The measured quantities $k_{\mathrm{eff}}, w_{\mathrm{e}}$ and $N D_{\mathrm{L}}$ in pure $\mathrm{N}_{2}$ and $\mathrm{CO}_{2}$ are compared to the same quantities calculated with Bolsig+ using the cross section sets

Table 1. Overview of the measurements in diluted $\mathrm{SF}_{5} \mathrm{CF}_{3} / \mathrm{N}_{2}$ and $\mathrm{SF}_{5} \mathrm{CF}_{3} / \mathrm{CO}_{2}$ mixtures.

\begin{tabular}{|c|c|c|c|}
\hline \multicolumn{4}{|c|}{$\begin{array}{l}\text { buffer } \mathrm{SF}_{5} \mathrm{CF}_{3} \\
\text { gas } \mathrm{mol}_{0}(E / N) \text {-range pressures } \\
(\mathrm{Td}) \\
(\mathrm{kPa})\end{array}$} \\
\hline \multirow[t]{4}{*}{$\mathrm{N}_{2}$} & 0 & $5-130$ & 2,10 \\
\hline & 0.02 & $15-130$ & $2,6,10$ \\
\hline & 0.09 & 40-135 & $2,6,10$ \\
\hline & 0.51 & $140-163$ & 10 \\
\hline \multirow[t]{3}{*}{$\mathrm{CO}_{2}$} & 0 & $5-120$ & 2,10 \\
\hline & 0.02 & $20-105$ & 10 \\
\hline & 0.09 & $30-110$ & $2,6,10$ \\
\hline
\end{tabular}



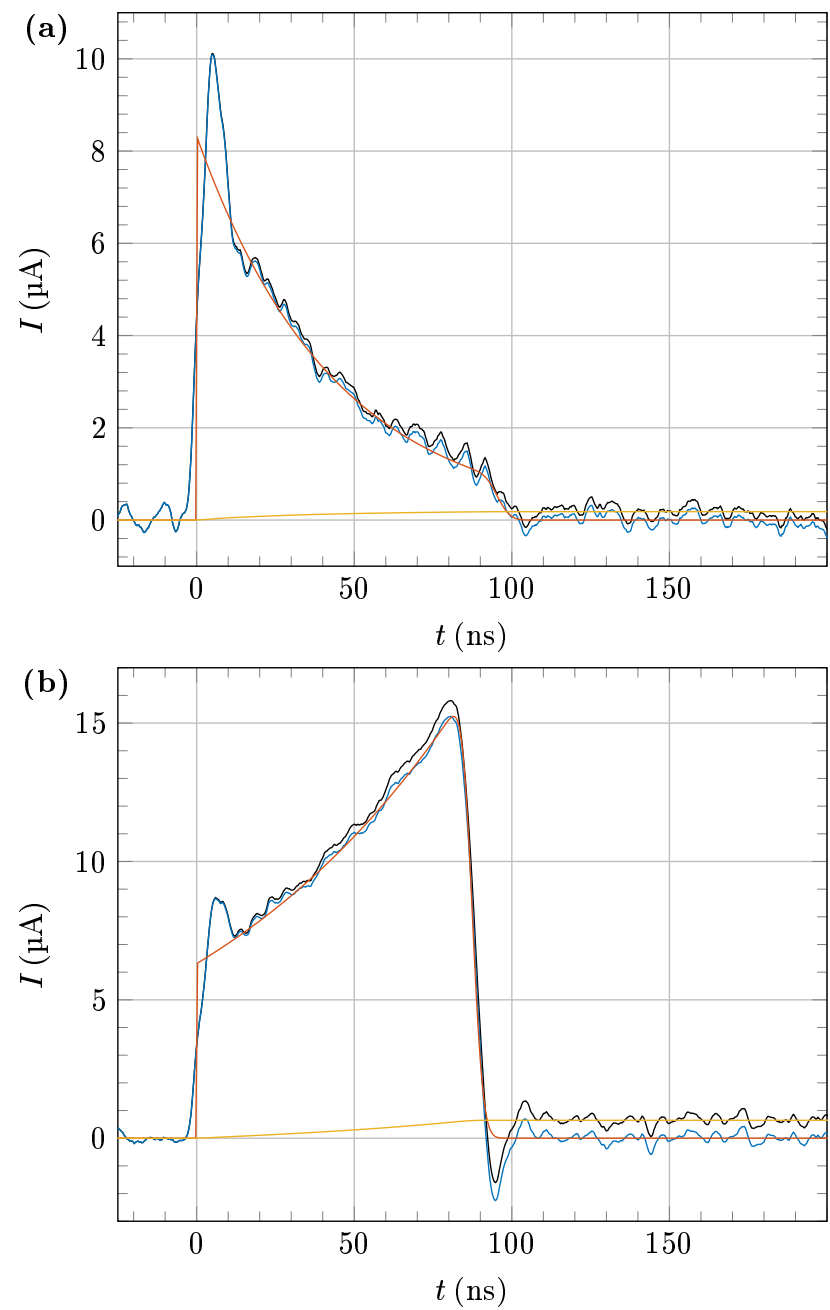

\begin{tabular}{ll|}
$-\quad$ measured current \\
electron current \\
ion current \\
fit of electron current model (1)
\end{tabular}

Figure 2. Currents versus time in the mixture of $0.51 \%$ $\mathrm{SF}_{5} \mathrm{CF}_{3}$ in $\mathrm{N}_{2}$, at a pressure of $10 \mathrm{kPa}$, for an electrode spacing of $15 \mathrm{~mm}$, and for a reduced electric field $E / N$ of (a) $147 \mathrm{Td}$ and (b) $163 \mathrm{Td}$.

of Biagi [32] and Phelps [33] respectively. There is a good overall agreement between our measurements and the calculations, except for the electron drift velocity in $\mathrm{CO}_{2}$ at $E / N$ ratios above $50 \mathrm{Td}$. For this $E / N$ range, our measurements are rather in agreement with calculations using the cross section set Siglo [36].

The measured values of $k_{\text {eff }}$ in $\mathrm{SF}_{5} \mathrm{CF}_{3} / \mathrm{N}_{2}$ and $\mathrm{SF}_{5} \mathrm{CF}_{3} / \mathrm{CO}_{2}$ mixtures shown in figures $3(\mathrm{a})$ and $4(\mathrm{a})$ are compared to calculated values of $k_{\text {eff }}$ in the same mixtures using the attachment and ionization cross sections of $\mathrm{SF}_{5} \mathrm{CF}_{3}[19,18]$ as explained in section 1.3. There is an excellent agreement between the measured and calculated values.

The effective ionization rate coefficient $k_{\text {eff }}$ shown in figures $3(\mathrm{a})$ and $4(\mathrm{a})$ is increasingly negative with
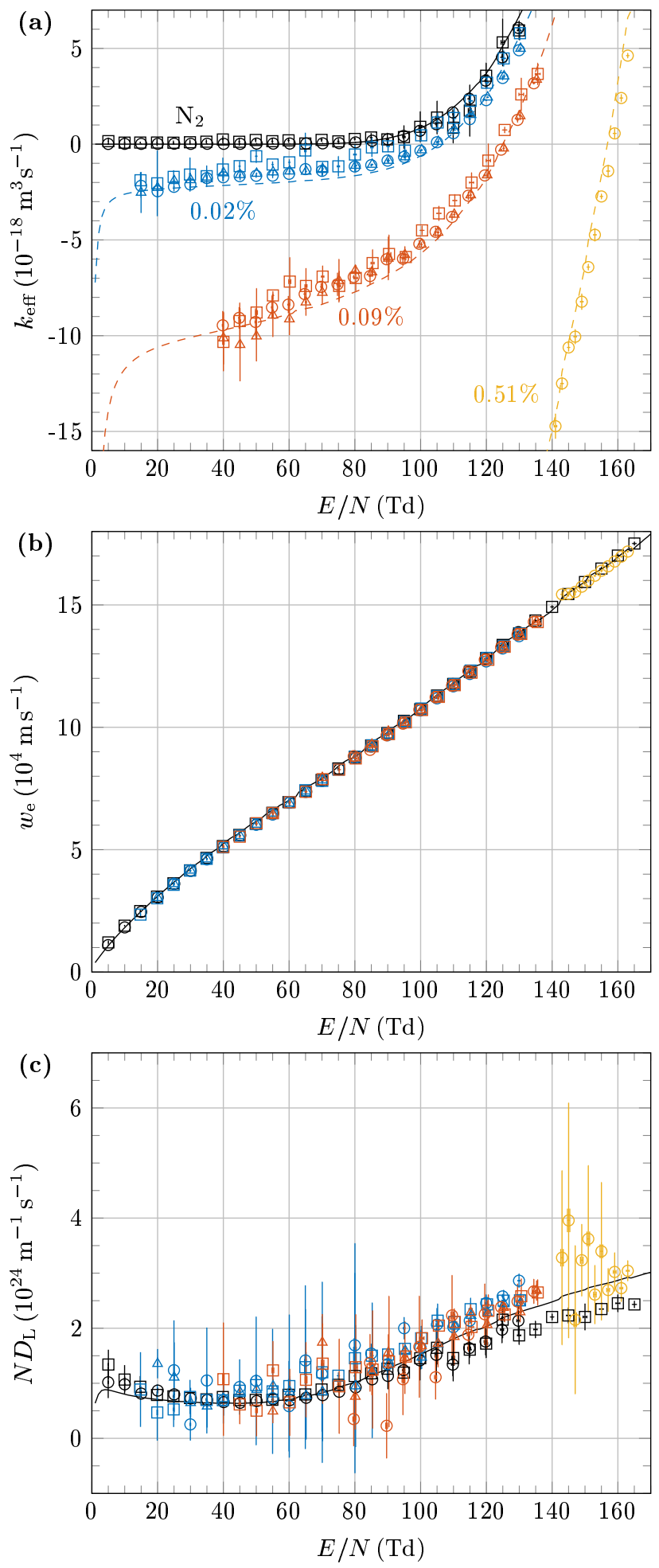

Figure 3. (a) Effective ionization rate coefficient, (b) electron drift velocity and (c) density normalized longitudinal electron diffusion coefficient versus $E / N$ in diluted $\mathrm{SF}_{5} \mathrm{CF}_{3} / \mathrm{N}_{2}$ mixtures. The gas mixtures are color-coded: the percentages of $\mathrm{SF}_{5} \mathrm{CF}_{3}$ are indicated in figure (a) and the same color code is used for figures (b) and (c). The markers are the present measured values at different gas pressures $(\square 2 \mathrm{kPa}, \triangle 6 \mathrm{kPa}, \circ 10 \mathrm{kPa})$. The lines are calculated as indicated in section 1.3: — Bolsig+ calc. using data from ref. [32], - - - calc. with equation (7) using data from refs. [18, 19, 32]. 

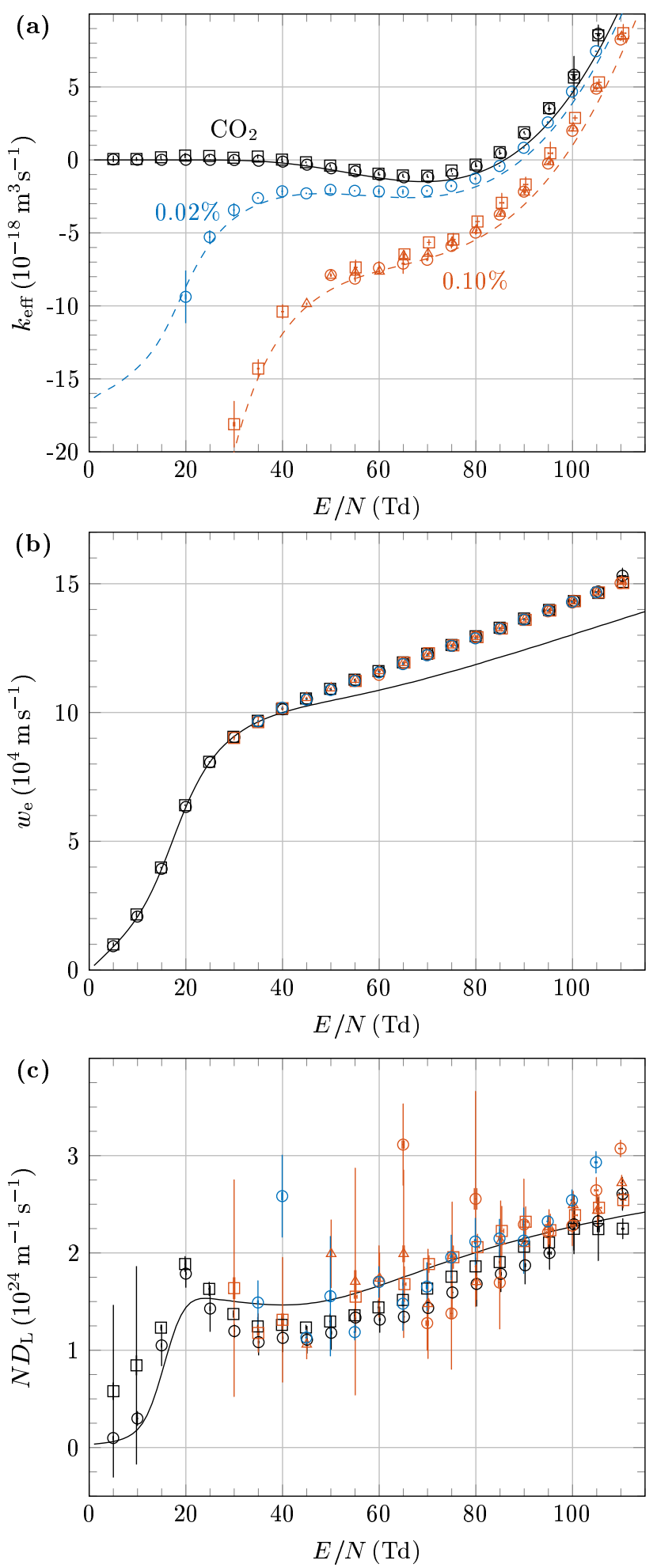

Figure 4. (a) Effective ionization rate coefficient, (b) electron drift velocity and (c) density normalized longitudinal electron diffusion coefficient versus $E / N$ in diluted $\mathrm{SF}_{5} \mathrm{CF}_{3} / \mathrm{CO}_{2}$ mixtures. The gas mixtures are color-coded: the percentages of $\mathrm{SF}_{5} \mathrm{CF}_{3}$ are indicated in figure (a) and the same color code is used for figures (b) and (c). The markers are the present measured values at different gas pressures $(\square 2 \mathrm{kPa}, \Delta 6 \mathrm{kPa}, \circ$ $10 \mathrm{kPa}$ ). The lines are calculated as indicated in section 1.3: — Bolsig + calc. using data from ref. [33], - - - calc. with equation (7) using data from refs. [18, 19, 33]. increasing mole fraction of $\mathrm{SF}_{5} \mathrm{CF}_{3}$, due to electron attachment to $\mathrm{SF}_{5} \mathrm{CF}_{3}$. Accordingly, a large increase of the density-reduced critical electric field $(E / N)_{\text {crit }}$ with increasing mole fraction of $\mathrm{SF}_{5} \mathrm{CF}_{3}$ can be observed. The electron drift velocity and diffusion coefficient in the diluted $\mathrm{SF}_{5} \mathrm{CF}_{3}$ mixtures are identical to the same quantities in the pure buffer gases. It was expected that adding a small amount of $\mathrm{SF}_{5} \mathrm{CF}_{3}$ would not affect the electron transport (drift and diffusion). The measured quantities $k_{\mathrm{eff}}, w_{\mathrm{e}}$ and $N D_{\mathrm{L}}$ show no dependence on the gas pressure in the investigated pressure range of 2 to $10 \mathrm{kPa}$.

\subsection{Electron attachment cross section of $\mathrm{SF}_{5} \mathrm{CF}_{3}$}

The measured values of $k_{\text {eff }}$ in the diluted $\mathrm{SF}_{5} \mathrm{CF}_{3} / \mathrm{N}_{2}$ and $\mathrm{SF}_{5} \mathrm{CF}_{3} / \mathrm{CO}_{2}$ mixtures are used to estimate the electron attachment cross section $\sigma_{\mathrm{a}}$ of $\mathrm{SF}_{5} \mathrm{CF}_{3}$ using the linear inversion and gaussian expansion methods mentioned in section 1.3. The resulting $\sigma_{\mathrm{a}}$ are shown in figure 5(a), and compared to the total attachment cross section of $\mathrm{SF}_{5} \mathrm{CF}_{3}$ measured in an electron beam experiment [19]. The electron attachment cross section of $\mathrm{SF}_{6}$ [20] is also plotted for comparison in the discussion section. The total ionization cross sections of $\mathrm{SF}_{5} \mathrm{CF}_{3}$ [18] and $\mathrm{SF}_{6}$ [21] are shown in figure 5(b).

In the electron energy range of 0.1 to $0.8 \mathrm{eV}$, the present results (linear inversion and gaussian expansion) are in good agreement with the beam measurement of $\mathrm{SF}_{5} \mathrm{CF}_{3}$. In the range below $0.1 \mathrm{eV}$ the present results are not reliable, therefore they are depicted using dotted lines in figure 5(a). For the gaussian expansion cross section, this error is due to the imposed shape of the cross section. For the linear inversion cross section, this error is likely due to the insufficient amount of electrons with these low energies at the minimum $E / N$ value that was measured, as has been previously discussed for the similar case of $\mathrm{SF}_{6}$ [29]. The linear inversion cross section result displays a narrow peak at $3.4 \mathrm{eV}$, which barely comes above the sensitivity limit of the method (5\% of maximal peak value), but contributes significantly to electron attachment at high $E / N$ ratios, such as the range of 140 to $163 \mathrm{Td}$ in the $\mathrm{N}_{2}$ mixture. This peak is almost one order of magnitude higher than the peak at $3.5 \mathrm{eV}$ measured in the beam experiment. Similarly, for the gaussian expansion cross section the second peak is shifted (to $5.4 \mathrm{eV}$ ) and has a too high amplitude compared to the beam cross section. Further errors in the present results could be due to non-negligible modification of the EEDF of $\mathrm{N}_{2}$ and $\mathrm{CO}_{2}$ by the $\mathrm{SF}_{5} \mathrm{CF}_{3}$ admixtures. Despite this, the present results show that reasonable estimations of the order of magnitude and energy range of the total attachment cross section of gases can be obtained by these methods, when no direct measurement of the 

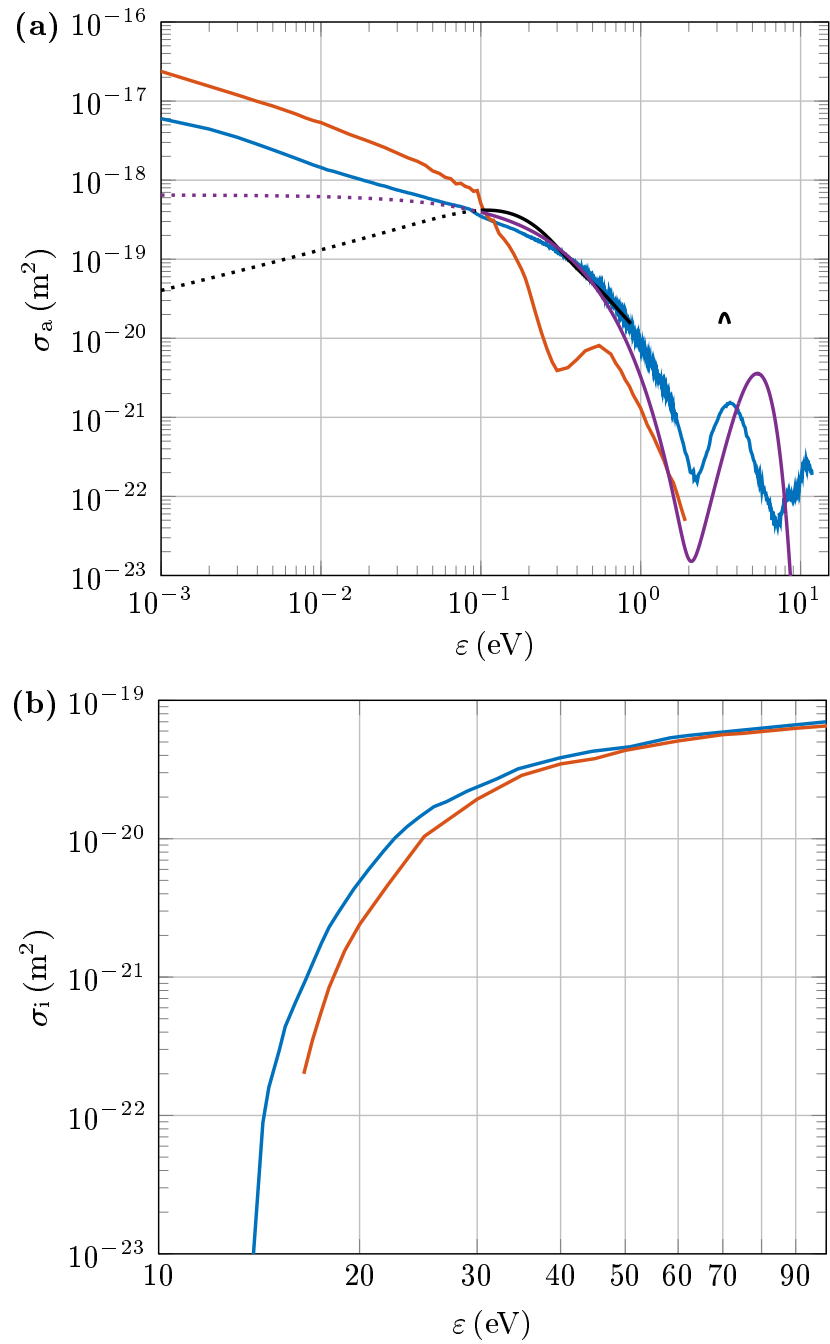

Figure 5. (a) Total attachment cross sections of $\mathrm{SF}_{5} \mathrm{CF}_{3}$ ...- linear inversion, ...- gaussian expansion, — ref. [19] (Graupner), and total attachment cross section of $\mathrm{SF}_{6}$ ref. [20] (Braun). (b) Total ionization cross section of $\mathrm{SF}_{5} \mathrm{CF}_{3}$ — ref. [18] (Chen), and of $\mathrm{SF}_{6}$ — ref. [21] (Christophorou).

attachment cross section is available.

\section{Mixtures with higher $\mathrm{SF}_{5} \mathrm{CF}_{3}$ content and pure $\mathbf{S F}_{5} \mathbf{C F}_{3}$}

An overview of the present measurements in $\mathrm{SF}_{5} \mathrm{CF}_{3} / \mathrm{N}_{2}$ and $\mathrm{SF}_{5} \mathrm{CF}_{3} / \mathrm{CO}_{2}$ mixtures with higher $\mathrm{SF}_{5} \mathrm{CF}_{3}$ content is given in table 2 .

\subsection{Sample measurements}

Figures 6(a) and (b) show sample current transients in pure $\mathrm{SF}_{5} \mathrm{CF}_{3}$. In contrast to the currents measured in mixtures with low $\mathrm{SF}_{5} \mathrm{CF}_{3}$ mole fractions, the amplitude of the ion current is of the same order of magnitude as that of the electron current. Since the ions are much slower than the electrons, it requires much more ions to generate a current of the same order of magnitude as the electron current. This indicates that both the ionization and attachment rate coefficients are large (many ions are formed), whereas their difference $k_{\text {eff }}=k_{\mathrm{i}}-k_{\mathrm{a}}$ is small in absolute value (the electron number varies comparatively less).

\subsection{Results of the electron current analysis}

The effective ionization rate coefficient $k_{\text {eff }}$, the electron drift velocity $w_{\mathrm{e}}$ and the longitudinal electron diffusion coefficient $N D_{\mathrm{L}}$ obtained in the considered $\mathrm{SF}_{5} \mathrm{CF}_{3} / \mathrm{N}_{2}$ mixtures are shown in figure $7(\mathrm{a}),(\mathrm{b})$ and (c) respectively, and in figure $8(\mathrm{a}),(\mathrm{b})$ and (c) for the $\mathrm{SF}_{5} \mathrm{CF}_{3} / \mathrm{CO}_{2}$ mixtures, and can also be downloaded from LXcat [17].

The quantities $k_{\mathrm{eff}}, w_{\mathrm{e}}$ and $N D_{\mathrm{L}}$ show no dependence on the gas pressure for the investigated pressures. The decrease of $k_{\text {eff }}$ with increasing mole fraction of $\mathrm{SF}_{5} \mathrm{CF}_{3}$ is clearly visible for the $\mathrm{SF}_{5} \mathrm{CF}_{3} / \mathrm{N}_{2}$ and $\mathrm{SF}_{5} \mathrm{CF}_{3} / \mathrm{CO}_{2}$ mixtures. The values of $w_{\mathrm{e}}$ in the $\mathrm{SF}_{5} \mathrm{CF}_{3} / \mathrm{N}_{2}$ mixture show a smooth transition from pure $\mathrm{N}_{2}$ to pure $\mathrm{SF}_{5} \mathrm{CF}_{3}$, whereas the values of $N D_{\mathrm{L}}$ are much more erratic. The electron diffusion coefficient $N D_{\mathrm{L}}$ is the quantity with the largest

Table 2. Overview of the measurements in the $\mathrm{SF}_{5} \mathrm{CF}_{3} / \mathrm{N}_{2}$ and $\mathrm{SF}_{5} \mathrm{CF}_{3} / \mathrm{CO}_{2}$ mixtures with higher $\mathrm{SF}_{5} \mathrm{CF}_{3}$ content.

\begin{tabular}{ccrr}
\hline \multicolumn{2}{c}{ buffer } \\
gas & $\mathrm{SF}_{5} \mathrm{CF}_{3}$ & \multicolumn{2}{c}{$(E / N)$-range } \\
mol\% & $(\mathrm{Td})$ & $\begin{array}{c}\text { pressures } \\
(\mathrm{kPa})\end{array}$ \\
\hline $\mathrm{N}_{2}$ & 0 & $5-180$ & 2,10 \\
& 4.96 & $212-232$ & 3,10 \\
& 10.4 & $261-271$ & 2,10 \\
& 20.1 & $310-318$ & 10 \\
& 40.2 & $396-401$ & 10 \\
& 59.1 & $453-458$ & 7 \\
& 74.6 & $500-505$ & 5 \\
& 100 & $545-577$ & 2,4 \\
\hline $\mathrm{CO}_{2}$ & 0 & $5-140$ & 2,10 \\
& 5.96 & $166-184$ & 10 \\
& 10.75 & $190-220$ & $2,6,10$ \\
\hline
\end{tabular}



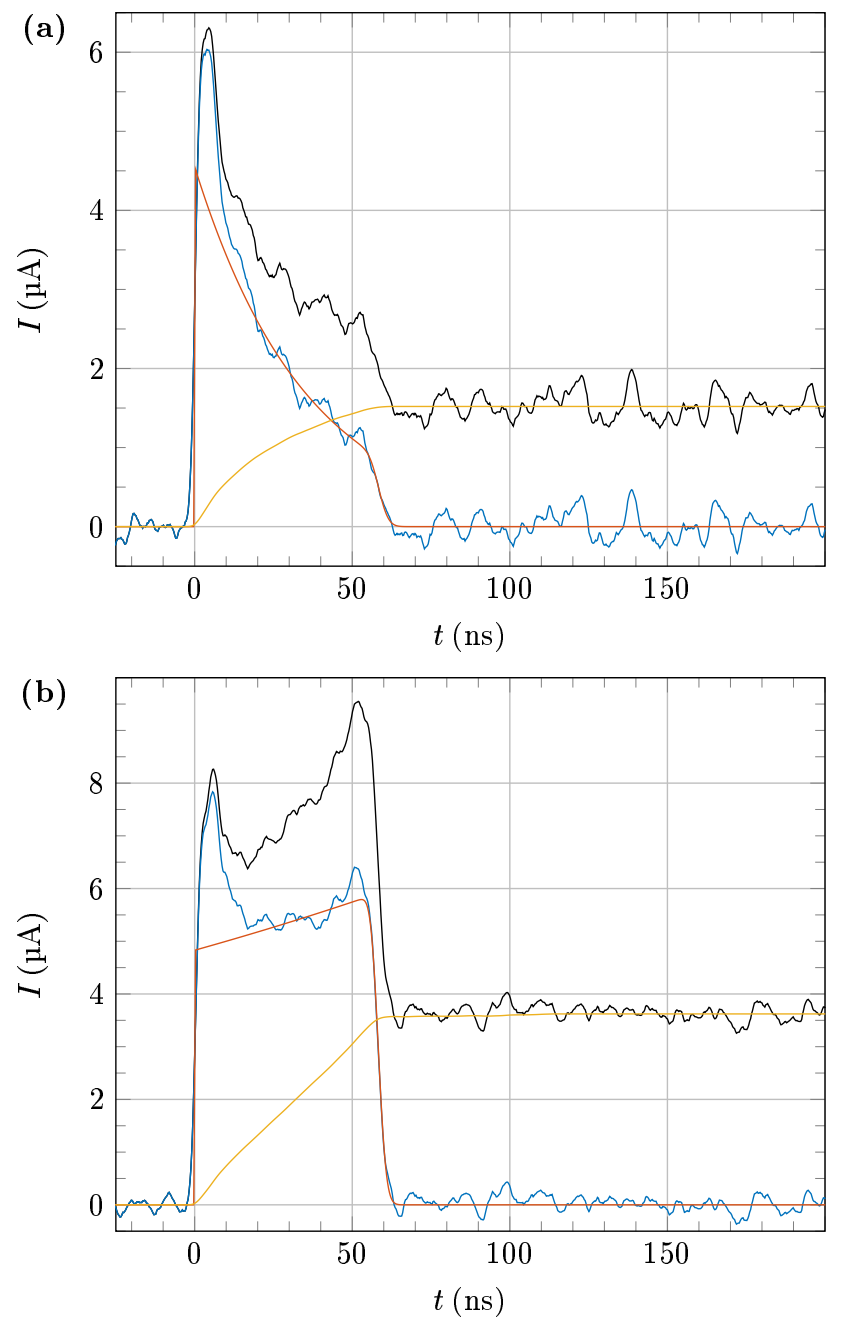

\begin{tabular}{|ll|}
$\square$ & $\begin{array}{l}\text { measured current } \\
\text { electron current } \\
\text { ion current } \\
\text { fit of electron current model }(1)\end{array}$ \\
\hline
\end{tabular}

Figure 6. Current versus time in pure $\mathrm{SF}_{5} \mathrm{CF}_{3}$, at a pressure of $4 \mathrm{kPa}$, for an electrode spacing of $15 \mathrm{~mm}$, and for a reduced electric field $E / N$ of (a) $573 \mathrm{Td}$ and (b) $577 \mathrm{Td}$.

uncertainty in the present experiment. It is determined by the slope of the falling edge of the waveform (see equation (1)), which is not very well resolved due to noise, limited signal bandwidth, and overshoots on the measured signal.

The present measurements can also be presented in the form of the reduced effective ionization coefficient $\alpha_{\text {eff }} / N$. Here, we derive $\alpha_{\text {eff }} / N$ simply as $\alpha_{\text {eff }} / N=k_{\text {eff }} / w_{\mathrm{e}}$. In fact, a more rigorous way to derive $\alpha_{\text {eff }} / N$ from bulk coefficients is [27, 25, 37]

$\alpha_{\text {eff }} / N=\frac{w_{\mathrm{e}}}{2 N D_{\mathrm{L}}}-\sqrt{\left(\frac{w_{\mathrm{e}}}{2 N D_{\mathrm{L}}}\right)^{2}-\frac{k_{\mathrm{eff}}}{N D_{\mathrm{L}}}}$,

but we dispensed from this correction in the present case because it amounts to less than $0.1 \%$ of $\alpha_{\text {eff }} / N$, which is negligible in comparison to the measurement
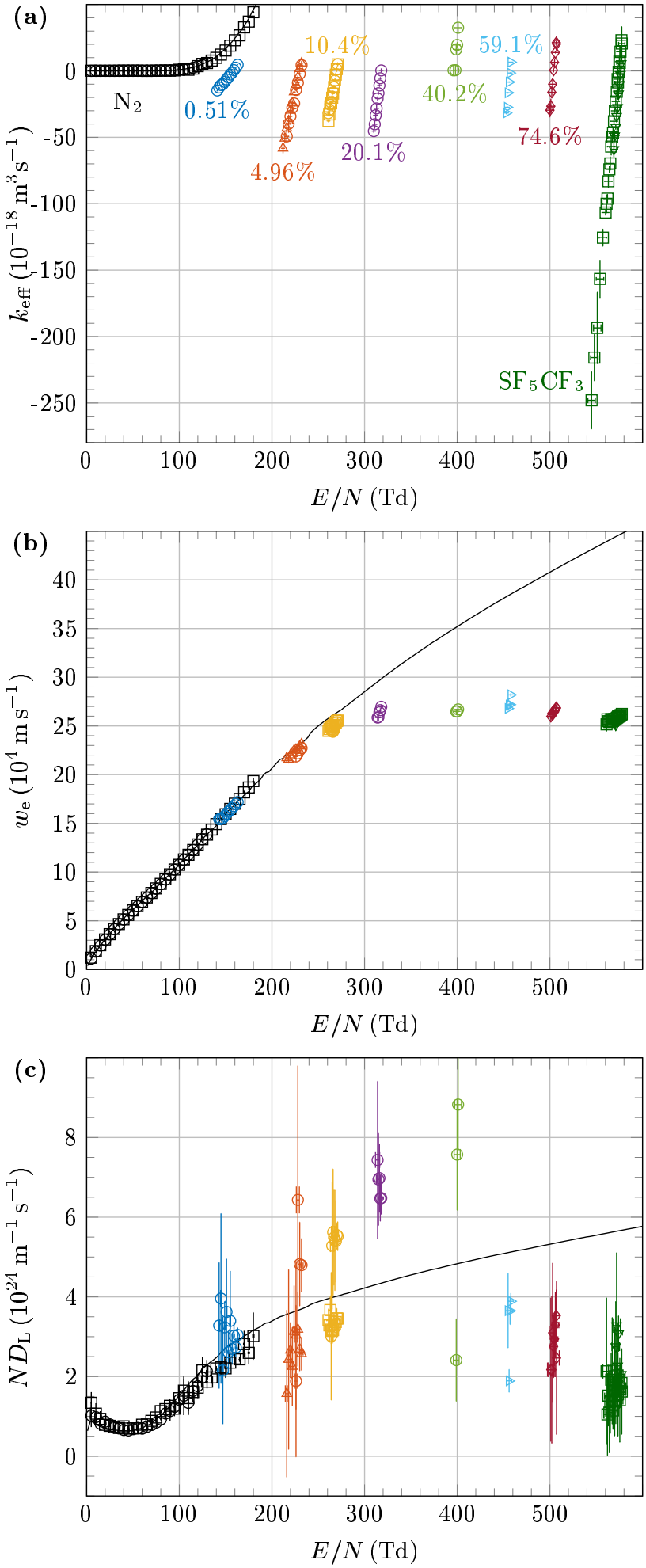

Figure 7. (a) Effective ionization rate coefficient, (b) electron drift velocity and (c) density normalized longitudinal electron diffusion coefficient versus $E / N$. The gas mixtures are color-coded: the percentages of $\mathrm{SF}_{5} \mathrm{CF}_{3}$ are indicated in figure (a) and the same color code is used for figures (b) and (c). The markers are the present measured values at different gas pressures $(\square 2 \mathrm{kPa}, \Delta 3 \mathrm{kPa}, \nabla 4 \mathrm{kPa}, \diamond 5 \mathrm{kPa}, \triangleright 7 \mathrm{kPa}, \diamond 10 \mathrm{kPa})$. The lines are calculation results in pure $\mathrm{N}_{2}$, obtained with the solver Bolsig + using the $\mathrm{N}_{2}$ cross section set from ref. [32]. 

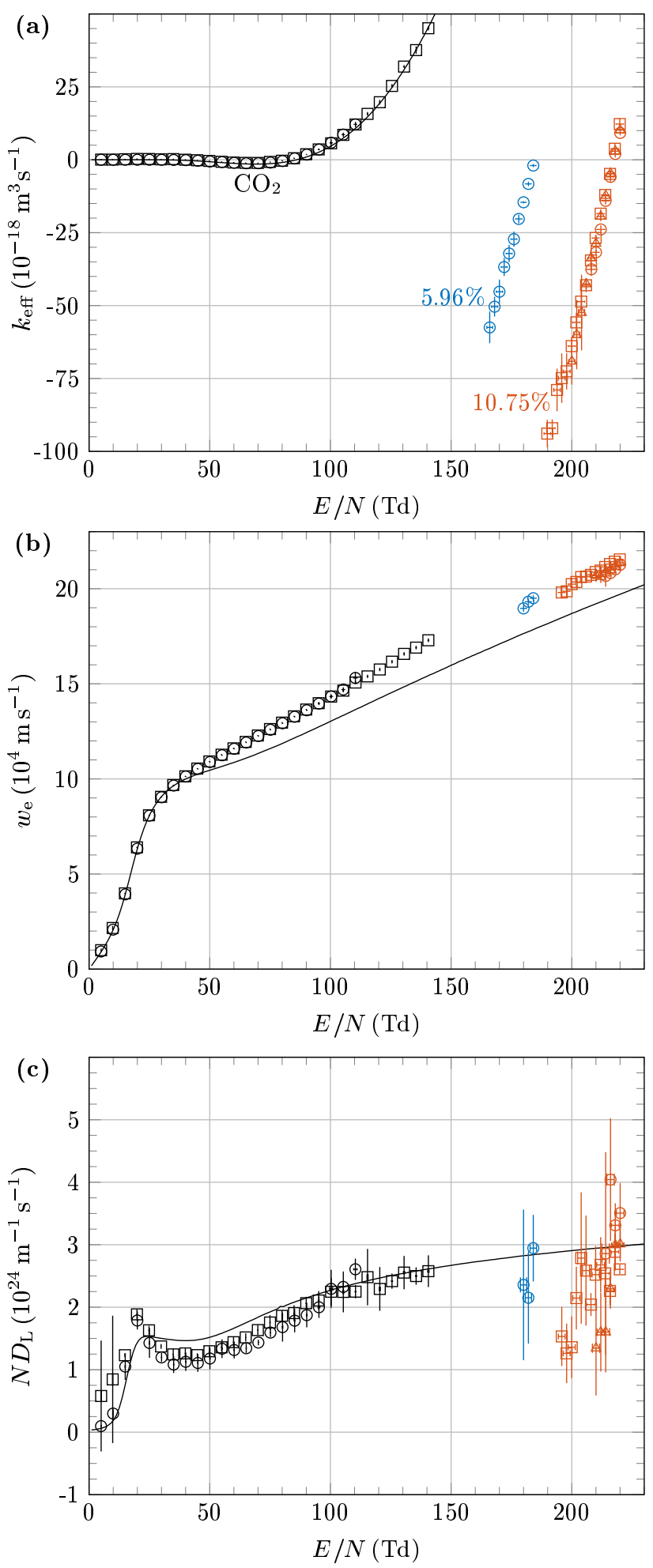

Figure 8. (a) Effective ionization rate coefficient, (b) electron drift velocity and (c) density normalized longitudinal electron diffusion coefficient versus $E / N$. The gas mixtures are color-coded: the percentages of $\mathrm{SF}_{5} \mathrm{CF}_{3}$ are indicated in figure (a) and the same color code is used for figures (b) and (c). The markers are the present measured values at different gas pressures $(\square 2 \mathrm{kPa}, \Delta 6 \mathrm{kPa}, \circ 10 \mathrm{kPa})$. The lines are calculation results in pure $\mathrm{CO}_{2}$, obtained with the solver Bolsig+ using the $\mathrm{CO}_{2}$ cross section set from ref. [33].

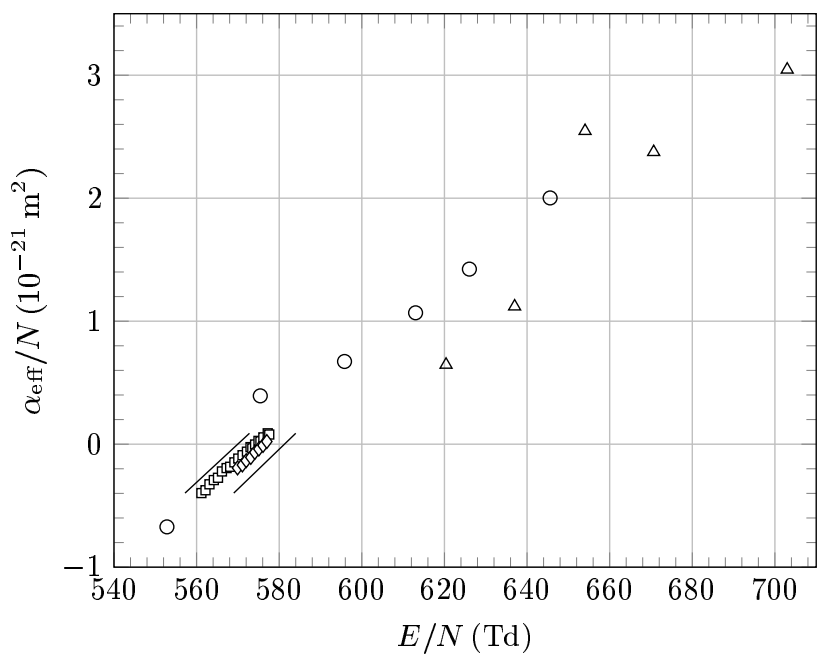

Figure 9. Reduced effective ionization coefficient in $\mathrm{SF}_{5} \mathrm{CF}_{3}$ as a function of $E / N$. Present results: $\diamond 2 \mathrm{kPa}, \square 4 \mathrm{kPa}$ (the error is represented by two solid lines). Values from ref. [22]: $\circ 0.6 \mathrm{kPa}, \triangle 0.8 \mathrm{kPa}$.

precision of around 10\%. The present values of $\alpha_{\text {eff }} / N$ are shown in figure 9 and compared to values measured by Harrison in 1953 using a steady-state Townsend setup [22]. An excellent agreement is observed between the present values and the values of $\alpha_{\text {eff }} / N$ at $0.6 \mathrm{kPa}$ from Harrison, despite the differences in the experimental and analysis techniques. The values from Harrison at $0.8 \mathrm{kPa}$ are somewhat lower, but given the experimental spread, the agreement with the present values is still reasonable.

\section{Discussion}

Ideally, insulating gases could be synthesized by substituting functional groups from a basis molecule to obtain the desired properties $[15,16]$. The comparison of $\mathrm{SF}_{5} \mathrm{CF}_{3}$ and $\mathrm{SF}_{6}$ gives an insight into the effect of replacing an $\mathrm{F}$ atom by a $\mathrm{CF}_{3}$ functional group. We discuss some properties of $\mathrm{SF}_{5} \mathrm{CF}_{3}$ and $\mathrm{SF}_{6}$ which are relevant for electrical insulation, based on the present study and on multiple other results from the literature, and we conclude on the insulation capability of $\mathrm{SF}_{5} \mathrm{CF}_{3}$ resulting from all these aspects.

Attachment properties In contrast to $\mathrm{SF}_{6}$, the electron attachment to $\mathrm{SF}_{5} \mathrm{CF}_{3}$ is exclusively dissociative, even at thermal electron energies $(\sim 0.03 \mathrm{eV})[19,16]$. The main anion formed by electron attachment to $\mathrm{SF}_{5} \mathrm{CF}_{3}$ is $\mathrm{SF}_{5}^{-}$. At thermal energies and up to $0.15 \mathrm{eV}$, the attachment cross section of $\mathrm{SF}_{5} \mathrm{CF}_{3}$ is smaller than that of $\mathrm{SF}_{6}$, see figure 5(a). The thermal attachment rate coefficient to $\mathrm{SF}_{6}$ is $2.4 \times$ $10^{-13} \mathrm{~m}^{-3} \mathrm{~s}^{-1}$, three times larger than that of $\mathrm{SF}_{5} \mathrm{CF}_{3}$ $8.0 \times 10^{-14} \mathrm{~m}^{-3} \mathrm{~s}^{-1}$ [38]. However, from $0.15 \mathrm{eV}$ to 
$2 \mathrm{eV}$, the attachment cross section of $\mathrm{SF}_{5} \mathrm{CF}_{3}$ is larger than that of $\mathrm{SF}_{6}$, and this energy range is more representative for the typical electron energies in electrical discharges. Therefore, the attachment rate coefficient to $\mathrm{SF}_{5} \mathrm{CF}_{3}$ is higher than that of $\mathrm{SF}_{6}$ for $E / N$ values larger than a few Townsend. At $E / N=570 \mathrm{Td}$ the attachment rate coefficient in pure $\mathrm{SF}_{5} \mathrm{CF}_{3}$ can be estimated using the attachment coefficient $\eta / N=$ $4 \times 10^{-21} \mathrm{~m}^{2}$ from ref. [22] and the electron drift velocity $w_{\mathrm{e}}=2.5 \times 10^{5} \mathrm{~ms}^{-1}$ from the present work. This yields the value $k_{\mathrm{a}}=w_{\mathrm{e}} \eta / N=1 \times 10^{-15} \mathrm{~m}^{3} \mathrm{~s}^{-1}$, twice larger than the attachment rate coefficient in pure $\mathrm{SF}_{6}$ at the same $E / N$, namely $k_{\mathrm{a}}=4.6 \times 10^{-16} \mathrm{~m}^{3} \mathrm{~s}^{-1}$, obtained by a Bolsig + calculation using the cross section set from Biagi [32].

Ionization properties The ionization of $\mathrm{SF}_{5} \mathrm{CF}_{3}$ is, at least on the timescale of several microseconds, exclusively dissociative. The main cation formed is $\mathrm{CF}_{3}^{+}$with an appearance energy of $12.9 \mathrm{eV}$ [39]. In contrast, the main cation formed by ionization of $\mathrm{SF}_{6}$ is $\mathrm{SF}_{5}^{+}$[21] with an ionization energy of $15.7 \mathrm{eV}$. The ionization energy is smaller for $\mathrm{SF}_{5} \mathrm{CF}_{3}$ than for $\mathrm{SF}_{6}$ and the total ionization cross section of $\mathrm{SF}_{5} \mathrm{CF}_{3}$ is larger, see figure 5(b). Despite this, assumedly due to the different electron energy distributions in $\mathrm{SF}_{6}$ and $\mathrm{SF}_{5} \mathrm{CF}_{3}$, the ionization rate coefficient in $\mathrm{SF}_{5} \mathrm{CF}_{3}$ at $E / N=570 \mathrm{Td}$ is $k_{\mathrm{i}}=w_{\mathrm{e}} \alpha / N=1 \times 10^{-15} \mathrm{~m}^{3} \mathrm{~s}^{-1}$, twice smaller than the calculated value for $\mathrm{SF}_{6}$ at the same $E / N$, namely $2.2 \times 10^{-15} \mathrm{~m}^{3} \mathrm{~s}^{-1}$.

Density reduced critical electric field As a result of the larger attachment rate coefficient and the smaller ionization rate coefficient of $\mathrm{SF}_{5} \mathrm{CF}_{3}$, the effective ionization rate coefficient of $\mathrm{SF}_{5} \mathrm{CF}_{3}$ is lower than that of $\mathrm{SF}_{6}$. The density-reduced critical electric field of $\mathrm{SF}_{5} \mathrm{CF}_{3}$ is $570 \mathrm{Td}, 1.6$ times higher than that of $\mathrm{SF}_{6}$, namely $359 \mathrm{Td}$. The density reduced critical electric field of $\mathrm{SF}_{5} \mathrm{CF}_{3} / \mathrm{N}_{2}, \mathrm{SF}_{5} \mathrm{CF}_{3} / \mathrm{CO}_{2}, \mathrm{SF}_{6} / \mathrm{N}_{2}$ and $\mathrm{SF}_{6} / \mathrm{CO}_{2}$ mixtures as a function of the mole fraction of $\mathrm{SF}_{5} \mathrm{CF}_{3}$ or $\mathrm{SF}_{6}$ is shown in figure 10. A synergy is observed in all these mixtures. A mixture of about $30 \% \mathrm{SF}_{5} \mathrm{CF}_{3}$ in $\mathrm{N}_{2}$ has the same density-reduced critical electric field as $\mathrm{SF}_{6}$.

Vapor pressure The boiling point, vapor pressure and critical point of $\mathrm{SF}_{5} \mathrm{CF}_{3}$ were reported in [2]. The boiling point of $\mathrm{SF}_{5} \mathrm{CF}_{3}$ is $-20^{\circ} \mathrm{C}$, which is relatively high compared to the boiling point of $\mathrm{SF}_{6}$, namely $-64{ }^{\circ} \mathrm{C}$. The vapor pressures of $\mathrm{SF}_{5} \mathrm{CF}_{3}$ and $\mathrm{SF}_{6}$ [42] are shown in figure 11. The vapor pressure of $\mathrm{SF}_{5} \mathrm{CF}_{3}$ is lower than that of $\mathrm{SF}_{6}$ by about one order of magnitude.

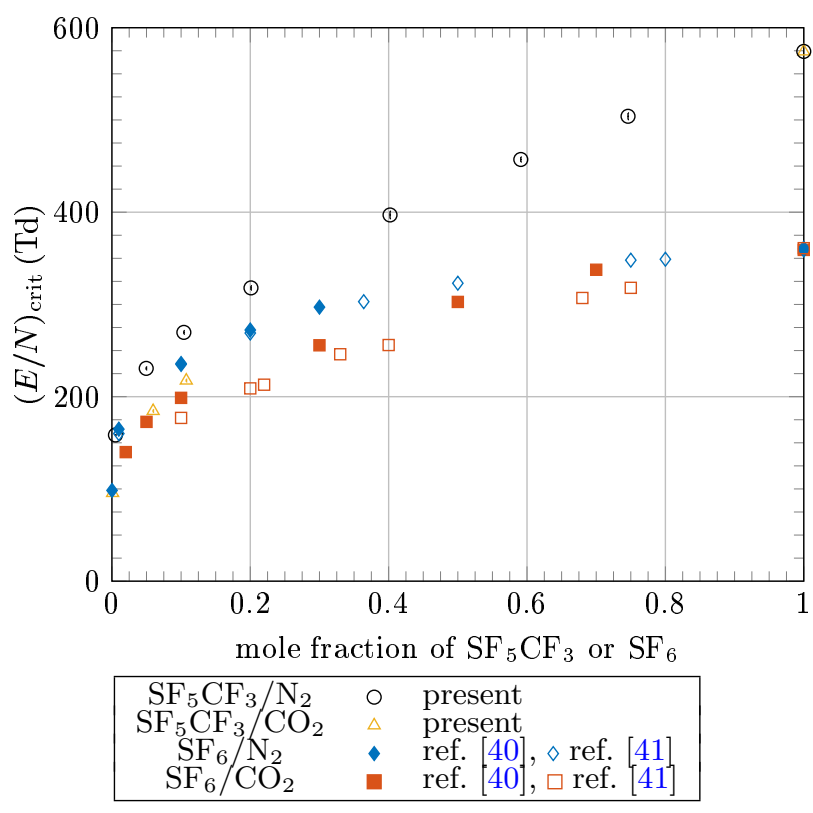

Figure 10. Density reduced critical electric field $(E / N)_{\text {crit }}$ as a function of the mole fraction of $\mathrm{SF}_{5} \mathrm{CF}_{3}$ or $\mathrm{SF}_{6}$ in $\mathrm{N}_{2}$ and $\mathrm{CO}_{2}$.

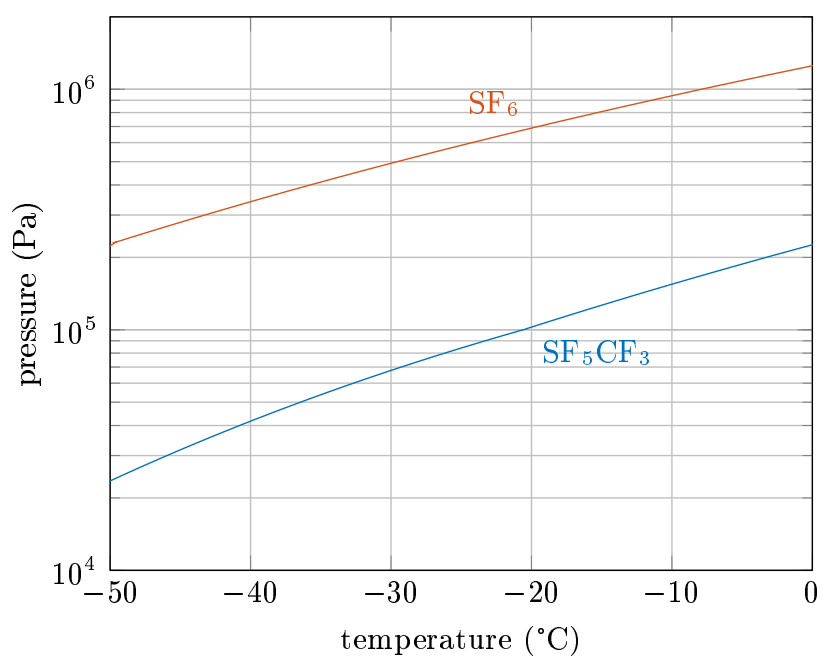

Figure 11. Vapor pressure curves of $\mathrm{SF}_{5} \mathrm{CF}_{3}$ and $\mathrm{SF}_{6}$.

Critical electric field Since the critical electric field $E_{\text {crit }}$ scales linearly with the gas pressure, it is important that insulating gases have high vapor pressures. The filling pressure of high voltage equipment is typically of $0.6 \mathrm{MPa}$ at $20^{\circ} \mathrm{C}$, and the minimum operating temperatures can be in the range of $-40{ }^{\circ} \mathrm{C}$ to $0^{\circ} \mathrm{C}$, typically $-25^{\circ} \mathrm{C}$. For medium voltage equipment the filling pressure is typically of $0.13 \mathrm{MPa}$ at $20^{\circ} \mathrm{C}$, and the minimum temperature is typically of $-25^{\circ} \mathrm{C}$. Considering the relatively low vapor pressure of $\mathrm{SF}_{5} \mathrm{CF}_{3}$, it has to be mixed with another gas to be used in medium or high voltage equipment. Figure 12(a) shows the critical electric 

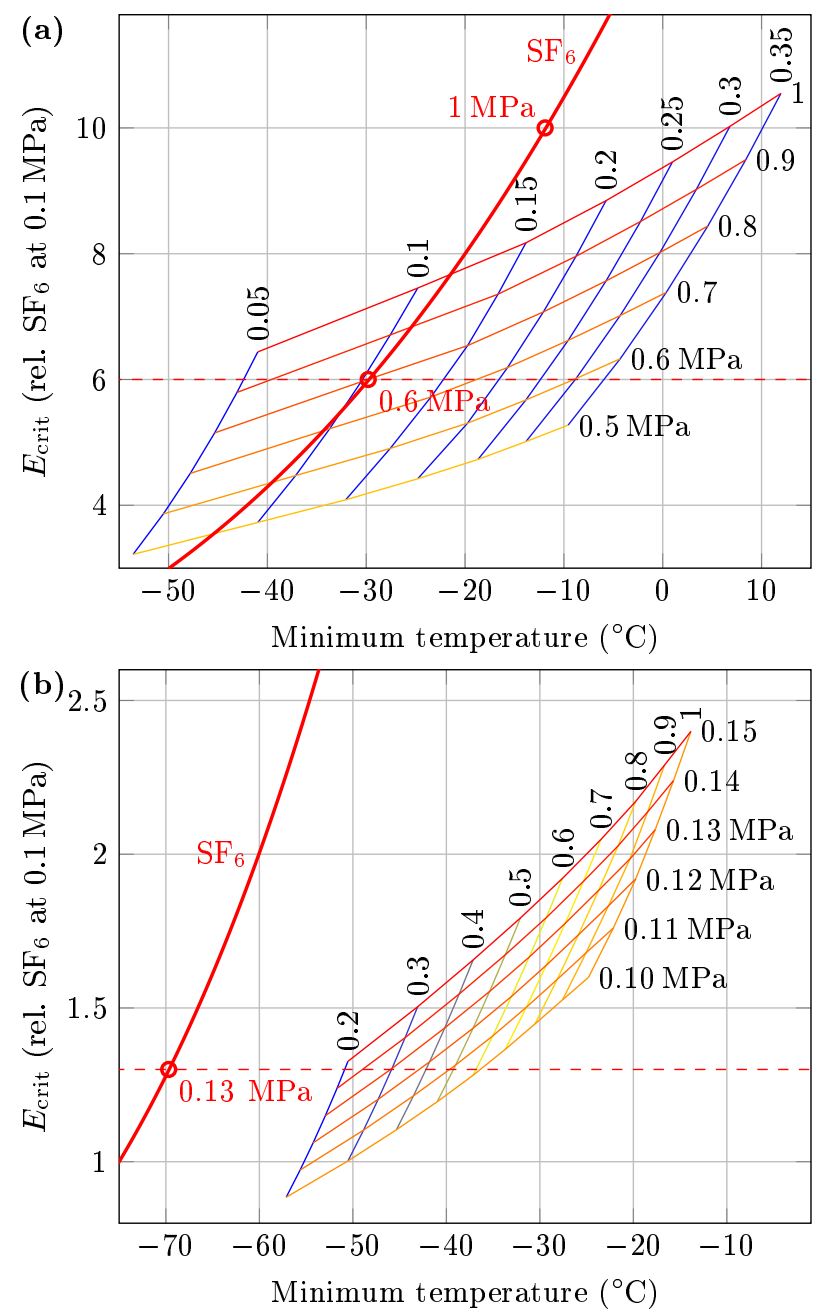

Figure 12. Critical electric field of $\mathrm{SF}_{5} \mathrm{CF}_{3} / \mathrm{N}_{2}$ mixtures relative to the critical electric field of $\mathrm{SF}_{6}$ at $p=0.1 \mathrm{MPa}$.

field of different $\mathrm{SF}_{5} \mathrm{CF}_{3} / \mathrm{N}_{2}$ mixtures as a function of the dew point of these mixtures, at the temperatures and pressures typical for high voltage applications. The mixtures contain 5 to $35 \% \mathrm{SF}_{5} \mathrm{CF}_{3}$ and different filling pressures from 0.5 to $1 \mathrm{MPa}$ are considered. For comparison, the critical electric field of pure $\mathrm{SF}_{6}$ at different filling pressures is plotted as a function of the dew point of $\mathrm{SF}_{6}$. The values of $E_{\text {crit }}$ in figure 12 are relative to the critical field of $\mathrm{SF}_{6}$ at $0.1 \mathrm{MPa}$, and the pressures are the filling pressures at a temperature of $20^{\circ} \mathrm{C}$. From figure 12 (a) can be read that a mixture of about $30 \% \mathrm{SF}_{5} \mathrm{CF}_{3}$ at $0.6 \mathrm{MPa}$ in $\mathrm{N}_{2}$ has the same critical electric field as $\mathrm{SF}_{6}$ at $0.6 \mathrm{MPa}$, but has a dew point (minimum temperature) of $-9^{\circ} \mathrm{C}$, whereas that of $\mathrm{SF}_{6}$ is $-30^{\circ} \mathrm{C}$. Similarly, a mixture of about $10 \%$ $\mathrm{SF}_{5} \mathrm{CF}_{3}$ at $0.8 \mathrm{MPa}$ in $\mathrm{N}_{2}$ has the same critical electric field and minimum operating temperature as $\mathrm{SF}_{6}$ at $0.6 \mathrm{MPa}$. Therefore, $\mathrm{SF}_{5} \mathrm{CF}_{3}$ could only replace $\mathrm{SF}_{6}$ in high voltage equipment at the cost of increasing the filling pressure or the minimum operating temperature.
Figure 12(b) shows the critical electric field of different $\mathrm{SF}_{5} \mathrm{CF}_{3} / \mathrm{N}_{2}$ mixtures as a function of the dew point of these mixtures, at the temperatures and pressures typical for medium voltage applications. The mixtures contain 20 to $100 \% \quad \mathrm{SF}_{5} \mathrm{CF}_{3}$ and different filling pressures from 0.10 to $0.15 \mathrm{MPa}$ are considered. From figure 12(b) can be read that the mixture of about $30 \%$ $\mathrm{SF}_{5} \mathrm{CF}_{3}$ at $0.13 \mathrm{MPa}$ performs as well as pure $\mathrm{SF}_{6}$ at $0.13 \mathrm{MPa}$, and has still a low minimum temperature of $-45^{\circ} \mathrm{C}$.

Global warming potential The radiative efficiency of $\mathrm{SF}_{5} \mathrm{CF}_{3}$ is of $0.59 \mathrm{Wm}^{-2} \mathrm{ppb}^{-1}$, slightly higher than that of $\mathrm{SF}_{6}$, namely $0.57 \mathrm{Wm}^{-2} \mathrm{ppb}^{-1}$ [9]. However, due to the shorter estimated lifetime of $\mathrm{SF}_{5} \mathrm{CF}_{3}$ compared to $\mathrm{SF}_{6}, 800$ years and 3200 years respectively, the GWP of $\mathrm{SF}_{5} \mathrm{CF}_{3}$ on a 100 year time horizon is 17400 , slightly lower than that of $\mathrm{SF}_{6}$, namely 23500 . The difference is accentuated when one considers that $\mathrm{SF}_{5} \mathrm{CF}_{3}$ would be not be used as a pure gas, but as part of a gas mixture, and therefore used in lesser amounts.

\section{Conclusion}

This work provides new experimental data of $\mathrm{SF}_{5} \mathrm{CF}_{3}$, which are in good agreement with existing data from previous beam and swarm measurements. It extends previous data to mixtures of $\mathrm{SF}_{5} \mathrm{CF}_{3}$ with $\mathrm{N}_{2}$ and $\mathrm{CO}_{2}$. In particular, a synergy is observed for the reduced critical electric field of $\mathrm{SF}_{5} \mathrm{CF}_{3}$ mixtures with $\mathrm{N}_{2}$ and $\mathrm{CO}_{2}$. In pure $\mathrm{SF}_{5} \mathrm{CF}_{3}$, the present data confirms and complements previous data by providing the electron drift velocity and diffusion in addition to the effective ionization rate coefficient. The possibility to estimate the attachment cross section using swarm measurements is demonstrated, and the obtained attachment cross sections are in reasonable agreement with existing beam cross sections.

By comparing the properties of $\mathrm{SF}_{6}$ with those of $\mathrm{SF}_{5} \mathrm{CF}_{3}$, it appears that the substitution of $\mathrm{F}$ by $\mathrm{CF}_{3}$ has many fold repercussions on the insulating properties. The substitution leads to an increased electric strength of $\mathrm{SF}_{5} \mathrm{CF}_{3}$, but as well to a higher boiling point. Consequently, $\mathrm{SF}_{5} \mathrm{CF}_{3}$ has to be used in a gas mixture, and the electric strength of that mixture depends largely on the synergism between $\mathrm{SF}_{5} \mathrm{CF}_{3}$ and the chosen buffer gas, an aspect which is not included in predictions of the electric strength. Considering all these aspects, it results that the superior electric strength of $\mathrm{SF}_{5} \mathrm{CF}_{3}$ is insufficient to compensate for its lower vapor pressure. This example highlights the importance of knowing with precision the boiling point of prospective replacement gases and their critical field in a gas mixture. The boiling point is an essential 
parameter which affects strongly the end result, yet even recent predictions of the boiling point of gases are still very imprecise $[14,15]$. Therefore, it is highly desirable to improve the prediction of the boiling point of gases, and to predict not only the electric strength of pure gases but as well possible synergy effect with buffer gases.

\section{Acknowledgments}

Thanks to professor Andreas Kornath at the Ludwig Maximilians University of Munich (Germany) for kindly providing us a sample of $\mathrm{SF}_{5} \mathrm{CF}_{3}$. We are also grateful to Dr. Martin-Walter Ruf and professor Hartmut Hotop from the Technical University of Kaiserslautern (Germany) for providing their data of the attachment cross section of $\mathrm{SF}_{5} \mathrm{CF}_{3}$ in numerical form. This work is financially supported by GE Grid (Switzerland) GmbH, Pfiffner Technologie AG, ABB Switzerland and Siemens AG.

\section{References}

[1] Silvey G A and Cady G H 1950 Journal of the American Chemical Society 72 3624-3626 URL http://dx.doi. org/10.1021/ja01164a084

[2] Beyerlein A L, DesMarteau D D, Kul I and Zhao G 1998 Fluid Phase Equilibria 150151287 - 296 ISSN 0378-3812 URL http://www.sciencedirect.com/ science/article/pii/S0378381298003288

[3] Geballe R and Linn F S 1950 Journal of Applied Physics 21 592-594 URL http://dx.doi.org/10.1063/1.1699712

[4] Busenberg E and Plummer L N 2010 Geochemistry, Geophysics, Geosystems 11 ISSN 1525-2027 URL 10. 1029/2010GC003312

[5] Sturges W T, Wallington T J, Hurley M D, Shine K P, Sihra K, Engel A, Oram D E, Penkett S A, Mulvaney R and Brenninkmeijer C A M 2000 Science 289 611-613 ISSN 0036-8075 URL http://science.sciencemag.org/ content/289/5479/611

[6] Kennedy R and Mayhew C 2001 International Journal of Mass Spectrometry 206 vii - x ISSN 13873806 URL http://www.sciencedirect.com/science/ article/pii/S1387380600004450

[7] Takahashi K, Nakayama T, Matsumi Y, Solomon S, Gejo T, Shigemasa E and Wallington T J 2002 Geophysical Research Letters 29 7-1-7-4 ISSN 1944-8007 URL http: //dx.doi.org/10.1029/2002GL015356

[8] Tsai W T 2007 Journal of Hazardous Materials 149747 751 ISSN 0304-3894 URL http://www.sciencedirect. com/science/article/pii/S0304389407012137

[9] Myhre G, Shindell D, Bréon F M, Collins W, Fuglestvedt $\mathrm{J}$, Huang J, Koch D, Lamarque J F, Lee D, Mendoza B, Nakajima T, Robock A, Stephens G, Takemura $\mathrm{T}$ and Zhang H 2013 Anthropogenic and Natural Radiative Forcing (Cambridge, United Kingdom and New York, NY, USA: Cambridge University Press) book section 8, pp 659-740 ISBN 978-1-107-66182-0 URL www.climatechange2013.org

[10] Earth system research laboratory - global monitoring division - halocarbons and other atmospheric trace species consulted 04.08.2016 URL www.esrl.noaa.gov/ gmd/hats/combined/SF6.html
[11] Elkins J W and Dutton G S August 2009 Nitrous oxide and sulphur hexafluoride vol 8 (Bulletin of the American Meteorological Society) pp 659-740 URL http://dx. doi.org/10.1175/BAMS-90-8-Stateof theClimate

[12] Meurice N, Sandre E, Aslanides A and Vercauteren D P 2004 IEEE Transactions on Dielectrics and Electrical Insulation 11 946-948 ISSN 1070-9878 URL http://dx. doi.org/10.1109/TDEI.2004.1387817

[13] Olivet A, Duque D and Vega L F 2007 Journal of Applied Physics 101023308 URL http://dx.doi.org/10.1063/ 1.2424532

[14] Rabie M, Dahl D A, Donald S M A, Reiher M and Franck C M 2013 IEEE Transactions on Dielectrics and Electrical Insulation 20 856-863 ISSN 1070-9878 URL http://dx.doi.org/10.1109/TDEI.2013.6518955

[15] Yu X, Hou H and Wang B 2017 Journal of Computational Chemistry 38 721-729 ISSN 1096-987X URL http:// dx.doi.org/10.1002/jcc.24741

[16] Sailer W, Drexel H, Pelc A, Grill V, Mason N, Illenberger E, Skalny J, Mikoviny T, Scheier $\mathrm{P}$ and Mrk T 2002 Chemical Physics Letters 35171 - 78 ISSN 0009-2614 URL http://www.sciencedirect.com/ science/article/pii/S0009261401013677

[17] ETHZ database URL www. Ixcat.net/ETHZ

[18] Chen C L, Wooton R E and Chantry P J 1982 Measured attachment and ionization cross sections and dielectric strength of SF5CF3 and C3F6 Proceedings of the 7th International Conference on Gas Discharges and their Applications pp 321-324

[19] Graupner K, Graham L, Field T, Mayhew C, Fabrikant I, Miller T, Braun M, Ruf M W and Hotop H 2008 International Journal of Mass Spectrometry 277113 122 ISSN 1387-3806 URL http://www.sciencedirect. com/science/article/pii/S1387380608002005

[20] Braun M, Marienfeld S, Ruf M W and Hotop H 2009 Journal of Physics B: Atomic, Molecular and Optical Physics 42125202 URL http://stacks.iop. org/0953-4075/42/i=12/a=125202

[21] Christophorou L G and Olthoff J K 2000 Journal of Physical and Chemical Reference Data 29 267-330 URL http://dx.doi.org/10.1063/1.1288407

[22] Harrison M A and Geballe R 1953 Phys. Rev. 91(1) 1-7 URL https://link.aps.org/doi/10.1103/PhysRev.91. 1

[23] Dahl D A, Teich T H and Franck C M 2012 Journal of Physics D: Applied Physics 45485201 URL http: //stacks. iop.org/0022-3727/45/i=48/a=485201

[24] Chachereau A, Rabie M and Franck C M 2016 Plasma Sources Science and Technology 25045005 URL http: //stacks . iop.org/0963-0252/25/i=4/a=045005

[25] Blevin H A and Fletcher J 1984 Australian Journal of Physics 37 593-600 URL https://doi.org/10.1071/ PH840593

[26] Robson R E 1991 Australian Journal of Physics 44 685-692 URL https://doi.org/10.1071/PH910685

[27] Tagashira H, Sakai Y and Sakamoto S 1977 Journal of Physics D: Applied Physics 101051 URL http:// stacks. iop. org $/ 0022-3727 / 10 / i=7 / a=011$

[28] Petrovi Z L, Dujko S, Mari D, Malovi G, Nikitovi, ai O, Jovanovi J, Stojanovi V and Radmilovi-Raenovi M 2009 Journal of Physics D: Applied Physics 42194002 URL http://stacks.iop.org/0022-3727/42/i=19/a=194002

[29] Rabie M, Haefliger P, Chachereau A and Franck C M 2015 Journal of Physics D: Applied Physics 48075201 URL http://stacks.iop.org/0022-3727/48/i=7/a=075201

[30] Hagelaar G and Pitchford L 2005 Plasma Sources Science and Technology 14 722-733 ISSN 0963-0252 URL http: //dx.doi.org/10.1088/0963-0252/14/4/011

[31] Lxcat plasma data exchange project URL www.lxcat.net

[32] Biagi database, data extracted from the fortran program 
MAGBOLTZ of S.F. Biagi, versions 8.9 and after, data retrieved on April 19, 2017 URL www.lxcat.net/Biagi

[33] Phelps database data retrieved on June 27, 2014 URL www.lxcat.net/Phelps

[34] Pitchford L C, Alves L L, Bartschat K, Biagi S F, Bordage M C, Bray I, Brion C E, Brunger M J, Campbell L, Chachereau A, Chaudhury B, Christophorou L G, Carbone E, Dyatko N A, Franck C M, Fursa D V, Gangwar R K, Guerra V, Haefliger P, Hagelaar G J M, Hoesl A, Itikawa Y, Kochetov I V, McEachran R P, Morgan W L, Napartovich A P, Puech V, Rabie M, Sharma L, Srivastava R, Stauffer A D, Tennyson J, de Urquijo J, van Dijk J, Viehland L A, Zammit M C, Zatsarinny O and Pancheshnyi S 2017 Plasma Processes and Polymers 14 1600098-n/a ISSN 1612-8869 1600098 URL http://dx.doi.org/10.1002/ppap.201600098

[35] Chantry P J and Wootton R E 1981 Journal of Applied Physics $\mathbf{5 2} 2731$ ISSN 00218979 URL http://scitation.aip.org/content/aip/journal/ jap/52/4/10.1063/1.329081

[36] Siglo database data retrieved on July 5, 2014 URL www. lxcat.net/Siglo

[37] Vass M, Korolov I, Loffhagen D, Pinho N and Donk Z 2017 Plasma Sources Science and Technology 26065007 URL http://stacks.iop.org/0963-0252/26/i=6/a=065007

[38] Mayhew C A, Critchley A D, Howse D C, Mikhailov V and Parkes M A 2005 The European Physical Journal D - Atomic, Molecular, Optical and Plasma Physics 35 307-312 ISSN 1434-6079 URL http://dx.doi.org/10. 1140/epjd/e2005-00087-7

[39] Gstir B, Hanel G, Fedor J, Probst M, Scheier P, Mason N J and Mrk T D 2002 Journal of Physics B: Atomic, Molecular and Optical Physics 352567 URL http:// stacks . iop. org/0953-4075/35/i=11/a=314

[40] UNAM database data retrieved on January 27, 2017 URL www. Ixcat.net/UNAM

[41] Aschwanden T 1985 PhD dissertation, ETH Zurich URL http://e-collection.library.ethz.ch/view/eth: 36996

[42] Guder C and Wagner W 2009 Journal of Physical and Chemical Reference Data 38 33-94 URL http://dx. doi.org/10.1063/1.3037344 